\title{
Relationship Between Dietary Self-Efficacy and Religiosity Among Seventh-Day Adventists in Peru
}

\author{
Jacksaint Saintila (D)', Yaquelin E Calizaya-Milla $\mathbb{D}^{\prime}$, Digna E Brañes-Ruiz ${ }^{2}$, Pedro R Nunura-Figueroa ${ }^{2}$, \\ Treisy C Chávez-Hernández', Vasthy A Bautista-Mayuri $\mathbb{D}^{\prime}$, Luz NR Santisteban-Murga $\mathbb{D}^{\prime}$, \\ Sergio E Calizaya-Milla $\mathbb{D}^{\prime}$, Laura E Baquedano-Santana $\mathbb{D}^{3}$ \\ 'Grupo de Investigación en Nutrición y Estilos de Vida, Escuela de Nutrición Humana, Universidad Peruana Unión, Lima, Perú; ${ }^{2}$ Departamento de \\ capellanía, Facultad de Ciencias de la Salud, Universidad Peruana Unión, Lima, Perú; ${ }^{3}$ Escuela de Posgrado, Facultad de Medicina Humana, Universidad \\ Nacional Mayor de San Marcos, Lima, Perú \\ Correspondence: Jacksaint Saintila, Escuela de Nutrición Humana, Universidad Peruana Unión, Chosica, Lima, I5, Perú, Tel +5I 99। 354 542, \\ Email jacksaintsaintila@upeu.edu.pe
}

Background: Most of the studies involving members of the Seventh-Day Adventist Church (SDA) have been conducted in the United States and Canada.

Aim: The purpose of the study was to explore the relationship between dietary self-efficacy and religiosity among SDA members in Peru.

Methods: In this online cross-sectional study, 403 participants aged 18 to 59 years selected by convenience were included. The data collected included sociodemographic information. In addition, the Dietary Self-Efficacy Scale (DIET-SE) and the Duke University Index of Religion (DUREL) were administered. A correlation analysis was performed and multiple linear regression was used to examine the association between religiosity, dietary self-efficacy, and sociodemographic variables.

Results: Dietary self-efficacy was significantly negatively correlated with all dimensions of religiosity, ie, organized religious activities (ORA), non-organized religious activities (NORA), and intrinsic religiosity (IR). In addition, participants had high dietary self-efficacy and religiosity.

Conclusion: Although religiosity dimensions did not significantly predict dietary self-efficacy, however, the non-organized religious activities dimension was the strongest predictor of dietary self-efficacy among Adventists in Peru. The present study will serve as a basis for future research to further investigate the potential positive effect of religiosity on the improvement a healthy diet and possible changes in the physical and mental health of the population.

Keywords: Adventists, diet, religion, religiosity, self-efficacy, Peru

\section{Introduction}

Dietary self-efficacy (DIET-SE) is defined as a perceived ability to make healthy food choices, even when faced with potential challenges. ${ }^{1}$ Unhealthy dietary choices represent an increased risk of noncommunicable diseases (NCDs). ${ }^{2}$ These diseases are the cause of approximately 5.5 million deaths per year in Latin America and the Caribbean, these numbers are equivalent to $80.7 \%$ of all deaths in the region. ${ }^{3}$ In Peru, according to data from the Instituto Nacional de Estadística e Informática, heart diseases represent the main cause of death. ${ }^{4}$ In 2020 , it was estimated that $41.1 \%$ of Peruvians over 15 years of age had a very high cardiovascular risk. ${ }^{5}$ Similarly, during the same year, in the same age group, an obesity prevalence of $24.6 \%$ was observed, which makes Peru one of the countries in the region with the highest prevalence. ${ }^{5}$

Adopting a healthy lifestyle, including a plant-based diet with plenty of minimally processed plant foods such as fruits, vegetables, nuts, and whole grains ${ }^{6}$ as well as the Mediterranean diet, with healthy foods such as fish and fermented or low-fat dairy products, may be beneficial in the prevention of NCDs. ${ }^{7}$ In contrast, studies have shown that foods high in saturated fats, free sugars, and sodium represent a major risk factor for NCDs, including cardiovascular 
disease, ${ }^{8}$ increased risk of overweight/obesity, ${ }^{9}$ type 2 diabetes mellitus, dyslipidemia, ${ }^{10}$ and different types of cancer. ${ }^{11}$ In addition, other research has indicated that excessive consumption of high-calorie dense foods, characterized by being poor in beneficial nutrients such as dietary fiber, vitamins, minerals, complex carbohydrates and bioactive elements, is associated with a higher probability of all-cause mortality. ${ }^{12}$

Religiosity is defined as a spiritual experience that expresses the behaviors of a given religion through specific beliefs, practices, and rituals. ${ }^{13}$ Several studies have demonstrated the positive influence of religiosity on lifestyle,${ }^{14}$ in healthy dietary patterns, ${ }^{15}$ and on people's health. ${ }^{16}$ Similarly, some studies have reported that a higher level of religiosity is associated with a lower risk of cardiovascular disease ${ }^{17}$ and some types of cancers. ${ }^{18}$ Moreover, studies report a positive association between religiosity and a lower risk of obesity and hypertension. ${ }^{19}$

Possible reasons to explain the positive association between religiosity and better health outcomes could be based on the fact that religions hold the body sacred and needs to be cared for through behaviors that promote health. ${ }^{20}$ Two of the main healthpromoting behaviors for religious people are regular physical activity and a healthy diet. ${ }^{21}$ Many religions adopt specific dietary rules and emphasize that the body is the temple of the Holy Spirit, which, in turn, can encourage members of the congregation to adopt healthy behaviors such as a balanced and equilibrated diet. ${ }^{20}$ In addition, most religions have specific dietary guidelines regarding which foods to eat or avoid; these guidelines are intended to improve physical, mental, and spiritual well-being. ${ }^{22}$ Two exemplary cases are the Seventh-day Adventist Church (SDA) and the Church of Jesus Christ of Latter-day Saints, where, according to their dietary rules, they encourage their believers to opt for a diet based on the consumption of plant-based foods such as fruits, vegetables, whole grains and less fat. ${ }^{19}$ Some observational studies show that Seventh-day Adventists, Mormons, and followers of religions with strict dietary guidelines have healthier eating habits, better physical health, and greater longevity than the general population. ${ }^{23}$ Likewise, those who report a high level of religiosity report a higher intake of fruits, vegetables, lower intake of saturated fats, ${ }^{24}$ less consumption of sugar-sweetened beverages, greater adherence to a healthy dietary pattern, and a better rate of healthy eating. ${ }^{20}$ The avoidance of any health risk behavior could be considered as one of the mechanisms to explain the association between religiosity and optimal physical health. Healthy dietary practices adopted by certain religions could be a protective factor in the prevention of diet-related diseases in the long term. ${ }^{22}$

Despite the importance of the positive influence of religion on food consumption, little research has been done on this topic. In Peru, to date, no study has examined the relationship between dietary self-efficacy and religiosity. In addition, although they have conducted a considerable number of studies on the diet and health of Adventists ${ }^{25,26}$ and some have studied the relationship between religiosity and health in ASD church members, ${ }^{27}$ however, these studies were mainly conducted in developed countries and not in developing countries such as Peru. Therefore, the purpose of this study was to evaluate the relationship between dietary self-efficacy and religiosity in ASDs in Peru.

\section{Materials and Methods}

\section{Research Design and Participants}

An online cross-sectional study on dietary self-efficacy and religiosity was conducted in 403 participants who are members of the SDA church in Peru. The non-probabilistic convenience sampling technique was used for the recruitment process. Microsoft Forms was used to create the survey. The study was conducted during the months of March and June 2021. Data collection was done by sending the survey link via email and social networks such as Facebook Messenger and WhatsApp. Furthermore, participants were invited to share the link to the study to recruit more participants. Participants under 18 years of age were excluded. Participants were informed of the purpose of the study through a brief description located on the home page of the survey. In addition, consent was obtained from participants by clicking on the "I wish to participate" option after reading the informed consent that was at the beginning of the survey. We did not collect the names and IP addresses of respondents. The survey was conducted anonymously and it was completely impossible to trace confidential data.

\section{Duke University Religion Index (DUREL)}

To measure the degree of religiosity of the participants, the Duke University Religion Index in Spanish was used. ${ }^{28}$ This questionnaire is made up of 5 items that classify the level of religious participation in three dimensions: organized 
religious activity (ORA), which consists of attending a church or other religious institution; non-organized religious activity (NORA), which refers to religious activities in private, such as praying, listening to religious programs, and the last dimension, intersectional religiosity (IR), which refers to the degree of personal religious commitment or motivation. The response categories for all items of the first two dimensions are organized on a 6-point Likert scale. The ORA dimension is the first item and presents Likert-type response options ranging from "never", scoring 1, to "more than once a week", which is scored 6 . The NORA dimension is the second item and starts from score 1 as "more than once a day" to 6 as "rarely or never". The IR dimension comprises the last three items of the scale and starts from score 1 as "definitely not true" to 5 as "definitely true". A higher score indicates high religiosity. The Spanish version validated in the Hispanic-American population was used. ${ }^{29}$ The psychometric properties of the original English version had a Cronbach's Alpha between 0.78 and 0.91 , indicating high reliability. ${ }^{29}$

\section{Dietary Self-Efficacy Scale (DIET-SE)}

For the measurement of dietary self-efficacy, the DIET-SE scale was used. ${ }^{30}$ The instrument is comprised of 11 items that measure the level of confidence a person has in their ability to resist a variety of food temptations and eat a healthy diet to promote an adequate weight. The scale has been translated into Spanish and subsequently validated in a study of 807 participants. ${ }^{2}$ The internal structure of the instrument is composed of three subscales: (1) high-caloric food (HCF), which considers questions 3, 6, 7, and 10 (describes situations in which the individual is exposed to tempting foods with high caloric density that may make it difficult to resist eating them); (2) social and internal factors (SIF), which regroups questions 1, 2, 5, and 9 (describes situations in which certain social or internal factors, such as being with friends or feeling tired, can make it difficult to resist the temptation to eat); and (3) the third subscale (negative emotional events, NEE), that regroups questions 4,8 , and 11 (describes situations in which emotional discomfort can be the cause of unplanned eating). The reliability of the instrument according to Cronbach's alpha for the three subscales, HCF, SIF, and EEN was $0.77,0.72$, and 0.70 , respectively. Responses are recorded using a Likert scale from 0 to 4 . The DIET-SE scale is evaluated by obtaining the mean scores of the total of the items included in each factor. Scores can range from 0 to 33 . A score of 20 or more was considered low dietary self-efficacy. ${ }^{2}$

\section{Sociodemographic Data}

The following sociodemographic variables were assessed by self-report: age (18 to 59 years), sex (female and male), place of origin (coast, jungle, and sierra), place of residence (urban and rural), marital status (married and single), degree of education (basic, technical, and university), age of baptism (years) $(\leq 10,11-20,21-30$, and $>30$ ), number of pastoral visit received at the last year (never, 1-2, 3-4, and $\geq 5$ ), and training on healthy eating in the last year (Yes or No).

\section{Statistical Analysis}

The collected data were verified, cleaned, and coded using Microsoft Excel. Subsequently, they were exported to IBM SPSS statistical software (version 22.4). For the descriptive statistical analysis of the data, the frequency, percentage, mean (M), and standard deviation (SD) were calculated. Pearson correlation coefficients were calculated to examine associations between variables. A linear regression analysis was carried out to explain dietary self-efficacy, using religiosity dimensions (ORA, NORA, and IR) and sociodemographic variables as independent variables. The $p$ values less than 0.05 were considered statistically significant.

\section{Results}

Data from 403 SDA church members residing in three regions of Peru were analyzed. We found that $65 \%(\mathrm{n}=262)$ were female, with a mean age of $32.99 \pm 13.41$ years and $35.2 \%(\mathrm{n}=261)$ were married, but there was a higher proportion of single women compared to men $(69.8 \%$ vs $55.3 \%, \mathrm{p}<0.05)$ (Table 1$)$. In addition, $83.1 \%(\mathrm{n}=335)$ were Adventists with university degrees, and those with between $\leq 10$ years and $11-20$ years of baptism accounted for $36 \%(\mathrm{n}=145)$ and $36.2 \%$ $(\mathrm{n}=146)$ of the sample, respectively. $40.2 \%(\mathrm{n}=162)$ did not receive any pastoral visits in the last year, this could be due to the COVID-19 pandemic, although the church followed its activities through the virtual platform Zoom Video Communications. However, $73.9 \%(\mathrm{n}=298)$ reported having received training on healthy eating in the last year, of 
Table I Number and Percentages of Participants According to Their Sociodemographic Characteristics

\begin{tabular}{|c|c|c|c|c|c|}
\hline \multirow[t]{2}{*}{ Characteristics } & \multicolumn{3}{|c|}{ Mean $\pm S D / n(\%)$} & \multirow[t]{2}{*}{$x^{2}$} & \multirow[t]{2}{*}{$P$ value* } \\
\hline & Women & Men & Total & & \\
\hline Age (years) & $30.85 \pm 12.09 / 262(65)$ & $36.97 \pm|4.82 /| 4 \mid$ & $32.99 \pm 13.4 \mid / 403(100)$ & & 0.000 \\
\hline Origin & & & & 5.865 & 0.053 \\
\hline Coast & $12 \mid(46.2)$ & $63(44.7)$ & $184(45.7)$ & & \\
\hline Jungle & $55(21.0)$ & $18(12.8)$ & $73(18.1)$ & & \\
\hline Sierra & $86(32.8)$ & $60(42.6)$ & $146(36.2)$ & & \\
\hline Place of residence & & & & 1.517 & 0.218 \\
\hline Urban & $210(80.2)$ & $120(85.1)$ & $330(81.9)$ & & \\
\hline Rural & $52(19.8)$ & $21(14.9)$ & $73(18.1)$ & & \\
\hline Marital status & & & & 8.478 & 0.004 \\
\hline Married & $79(30.2)$ & $63(44.7)$ & $142(35.2)$ & & \\
\hline Single & $183(69.8)$ & $78(55.3)$ & $261(64.8)$ & & \\
\hline Level of education & & & & 0.395 & 0.821 \\
\hline Basic & $26(9.9)$ & $15(10.6)$ & $4 I(10.2)$ & & \\
\hline Technical & $19(7.3)$ & $8(5.7)$ & $27(6.7)$ & & \\
\hline University & $217(82.8)$ & 118 (83.7) & $335(83.1)$ & & \\
\hline $\begin{array}{l}\text { Age of baptism } \\
\text { (years) }\end{array}$ & & & & 14.195 & 0.003 \\
\hline$\leq 10$ & $99(37.8)$ & $46(32.6)$ & $145(36.0)$ & & \\
\hline $\mathrm{II}-20$ & $105(40.1)$ & $41(29.1)$ & $146(36.2)$ & & \\
\hline $21-30$ & $35(13.4)$ & $26(18.4)$ & $61(15.1)$ & & \\
\hline$>30$ & $23(8.8)$ & $28(19.9)$ & $51(12.7)$ & & \\
\hline Pastoral visit ${ }^{\dagger}$ & & & & 5.760 & 0.124 \\
\hline No & $106(40.5)$ & $56(39.7)$ & $162(40.2)$ & & \\
\hline $\mathrm{I}-2$ & $62(23.7)$ & $32(22.7)$ & $94(23.3)$ & & \\
\hline $3-4$ & $31(11.8)$ & $8(5.7)$ & $39(9.7)$ & & \\
\hline$\geq 5$ & $63(24.0)$ & $45(31.9)$ & $108(26.8)$ & & \\
\hline Health training ${ }^{\ddagger}$ & & & & 4.858 & 0.028 \\
\hline Yes & $203(77.5)$ & $95(67.4)$ & 298 (73.9) & & \\
\hline No & $59(22.5)$ & $46(32.6)$ & $105(26.1)$ & & \\
\hline \multicolumn{6}{|l|}{ Religiosity } \\
\hline ORA & $5.17 \pm 1.084262(65)$ & $4.99 \pm \mathrm{I} .407 \mathrm{I} \mid \mathrm{I}$ (35) & $5.11 \pm 1.208403(100)$ & & 0.166 \\
\hline NORA & $4.45 \pm 1.300 / 262(65)$ & $4.33 \pm 1.602 / 141(35)$ & $4.41 \pm 1.412 / 403(100)$ & & 0.413 \\
\hline IR & $13.28 \pm 2.163 / 262(65)$ & $|2.99 \pm 2.445 / 14|$ & $13.18 \pm 2.267 / 403(100)$ & & 0.228 \\
\hline
\end{tabular}


Table I (Continued).

\begin{tabular}{|c|c|c|c|c|c|}
\hline \multirow[t]{2}{*}{ Characteristics } & \multicolumn{3}{|c|}{ Mean \pm SD/n (\%) } & \multirow[t]{2}{*}{$\mathbf{x}^{2}$} & \multirow[t]{2}{*}{$P$ value* } \\
\hline & Women & Men & Total & & \\
\hline DIET-SE & & & & 1.789 & 0.181 \\
\hline LDSE & $107(40.8)$ & $48(34.0)$ & 155 & & \\
\hline HDSE & I55 (59.2) & $93(66.0)$ & 248 (6I.5) & & \\
\hline
\end{tabular}

Note: $*_{p}<0.05$ (significant); ${ }^{\dagger}$ Number of pastoral visits received in the last year; ${ }^{\ddagger}$ Training on healthy eating in the last year.

Abbreviations: ORA, organized religious activities; NORA, unorganized religious activities; IR, intrinsic religiosity. DIET-SE, Dietary Self-Efficacy Scale; LDSE, low dietary self-efficacy; HDSE, high dietary self-efficacy.

which $77.5 \%(n=203)$ were female compared to males $(67.4 \%, n=95, p>0.05)$. High dietary self-efficacy was reported by $61.5 \%(\mathrm{n}=248)$ of the participants. Likewise, participants reported high religiosity, ie, $5.11 \pm 1.2,4.41 \pm 1.4$, and 13.18 \pm 2.2 , for the ORA, NORA, and IR dimensions, respectively. Finally, there were no differences in the dietary self-efficacy and religiosity variables according to the sex of the participants (see Table 1).

Table 2 shows the correlational analysis of the study variables. Dietary self-efficacy was significantly, negatively associated with all dimensions of religiosity, ie, ORA, NORA, and IR. Similarly, this variable was negatively correlated with the age of baptism and the age of the participants; however, a positive association with marital status was evidenced. Likewise, all correlations between the dimensions of religiosity were significant and positive. Specifically, organized religious activities were positively and strongly correlated with non-organized religious activities; in contrast, this religious component was positively and moderately correlated with intrinsic religiosity. In addition, organized religious activities were positively correlated with age at baptism, pastoral visit, and age of participants; however, a negative association was observed between dietary training in the last year, place of residence, and marital status. In particular, NORA was negatively associated with place of residence.

A multiple linear regression analysis was carried out to analyze the associations between religious variables and dietary self-efficacy. It was observed that the model was significant and explained $9 \%$ of the variance of dietary selfefficacy $(\mathrm{F}=3.515, \mathrm{gl}=11.391, \mathrm{p}<0.001)$. (Table 3$)$. Dietary self-efficacy was not significantly predicted by the religiosity dimensions, ie, ORA $(\beta=0.01, \mathrm{p}=0.844)$, NORA $(\beta=-0.13, \mathrm{p}=0.090)$, and IR $(\beta=-0.04, \mathrm{p}=0.451)$.

\section{Discussion}

Religiosity plays a fundamental role in the adoption of a healthy lifestyle that includes a balanced and equilibrated diet, which is important to prevent and control chronic non-communicable diseases, improve the functioning of the immune system, favor longevity, through the implementation of health promotion and disease prevention programs. ${ }^{20,21,24}$ The objective of this study was to evaluate the relationship between dietary self-efficacy and religiosity in members of the SDA Church in Peru.

The current study extends previous findings on the level of religiosity of Seventh-Day Adventists. The results of a survey of 509 black SDA church members in Canada found that the majority $(72 \%)$ stated that they participated in the biblical Sabbath rest. In addition, the majority $(75 \%)$ of respondents stated that they attended the church weekly. ${ }^{27}$ In the Peruvian context, this could be due to the fact that in all SDA churches in Peru, weekly meetings are held (Wednesdays and Fridays) in which short Bible studies are carried out - between fifteen to twenty minutes - or a presentation of some passages from the writings of the Spirit of Prophecy are carried out. ${ }^{31}$ In another study conducted in Seventh-Day Adventists found that the mean ORA, NORA and IR were $4.3 \pm 0.79,4.7 \pm 0.73,14.0 \pm 1.52$, respectively, ${ }^{20}$ which is consistent with our findings, where participants reported high religiosity, ie, 5.11 $\pm 1.2,4.41 \pm 1.4$, and 13.18 \pm 2.2 , for the ORA, NORA and IR dimensions, respectively.

In multiple regression analysis, religiosity dimensions did not significantly predict dietary self-efficacy. Similarly, in a similar study conducted among Seventh-day Adventists in West Malaysia, it was found that fruit and vegetable consumption was not predicted by religiosity/spirituality. ${ }^{20}$ The insignificant prediction observed in our study could be 
Table 2 Correlations Between Study Variables

\begin{tabular}{|c|c|c|c|c|c|c|c|c|c|c|c|c|c|}
\hline \multirow{2}{*}{\multicolumn{2}{|c|}{ Variable }} & $\mathbf{I}$ & 2 & 3 & 4 & 5 & 6 & 7 & 8 & 9 & 10 & 11 & 12 \\
\hline & & DIET-SE & ORA & NORA & IR & $\begin{array}{l}\text { Age of Baptism } \\
\text { (years) }\end{array}$ & $\begin{array}{l}\text { Pastoral } \\
\text { Visit }^{\dagger}\end{array}$ & $\begin{array}{l}\text { Health } \\
\text { Training }^{\ddagger}\end{array}$ & $\begin{array}{l}\text { Age } \\
\text { (Years) }\end{array}$ & Origin & $\begin{array}{l}\text { Place of } \\
\text { Residence }\end{array}$ & $\begin{array}{l}\text { Marital } \\
\text { Status }\end{array}$ & $\begin{array}{l}\text { Level of } \\
\text { Education }\end{array}$ \\
\hline I & DIET-SE & - & & & & & & & & & & & \\
\hline 2 & ORA & $-0.16 * * *$ & - & & & & & & & & & & \\
\hline 3 & NORA & $-0.2 I^{* * *}$ & $0.72^{* * * *}$ & - & & & & & & & & & \\
\hline 4 & IR & $-0.14 * *$ & $0.49 * * *$ & $0.50 * * *$ & - & & & & & & & & \\
\hline 5 & Age of baptism (years) & $-0.22^{* * * *}$ & $0.32 * * *$ & $0.36 * * *$ & $0.22 * * *$ & - & & & & & & & \\
\hline 6 & Pastoral visit ${ }^{\dagger}$ & -0.06 & $0.24 * * *$ & $0.24 * * *$ & $0.12 * *$ & $0.11 *$ & - & & & & & & \\
\hline 7 & Health training ${ }^{\ddagger}$ & 0.01 & $-0.22 * * *$ & $-0.24 * * *$ & $-0.19 * * *$ & $-0.08 *$ & $-0.21 * * *$ & - & & & & & \\
\hline 8 & Age (years) & $-0.26 * * *$ & $0.29 * * *$ & $0.33^{* * *}$ & $0.20 * * *$ & $0.72^{* * *}$ & $0.12^{* *}$ & -0.01 & - & & & & \\
\hline 9 & Origin & -0.06 & 0.04 & 0.05 & 0.02 & $0.09 *$ & -0.01 & -0.02 & $0.14 * *$ & - & & & \\
\hline 10 & Place of residence & 0.00 & $-0.03^{*}$ & $-0.08 *$ & 0.05 & $-0.11 *$ & -0.02 & -0.06 & -0.01 & $0.12 * *$ & - & & \\
\hline II & Marital status & $0.17 * * *$ & $-0.25 * * *$ & $-0.32 * * *$ & $-0.22 * * *$ & $-0.57^{* * *}$ & $-0.19 * * *$ & $0.08 *$ & $-0.62 * * *$ & $-0.12^{* *}$ & 0.00 & - & \\
\hline 12 & Level of education & 0.03 & 0.05 & 0.03 & 0.06 & $0.12 * *$ & -0.05 & $-0.13^{* *}$ & 0.02 & 0.05 & $-0.22 * * *$ & -0.01 & - \\
\hline
\end{tabular}

Note: $\mathrm{n}=403 ;{ }^{*}<0.05$ (significant); $* * 0.01$ (significant); ${ }^{* * *} \mathrm{p}<0.001$ (significant); ${ }^{\dagger}$ Number of pastoral visits received in the last year; ${ }^{*}$ Training on healthy eating in the last year.

Abbreviations: ORA, organized religious activities; NORA, non-organized religious activities; IR, intrinsic religiosity. DIET-SE, Dietary Self-Efficacy Scale. 
Table 3 Multiple Regression Analysis for Variables Predicting DIET-SE

\begin{tabular}{|c|c|c|c|c|c|c|c|c|}
\hline Characteristics & B & SE & $\beta$ & $t$ Value & $P$ value & $\mathbf{R}^{2}$ & Adjusted $\mathbf{R}^{2}$ & $F(d f 1, d f 2)$ \\
\hline Religiosity & & & & & & $0.09 * * *$ & 0.06 & 3.515 (11.391) \\
\hline ORA & 0.10 & 0.51 & 0.01 & 0.20 & 0.844 & & & \\
\hline NORA & -0.77 & 0.45 & -0.13 & -1.70 & 0.090 & & & \\
\hline $\mathbb{I R}$ & -0.16 & 0.22 & -0.04 & -0.75 & 0.451 & & & \\
\hline Age of baptism (years) & -0.46 & 0.62 & -0.05 & -0.74 & 0.462 & & & \\
\hline Pastoral visit ${ }^{\dagger}$ & -0.06 & 0.35 & -0.01 & -0.18 & 0.858 & & & \\
\hline Health training ${ }^{\ddagger}$ & -0.53 & 1.00 & -0.03 & -0.53 & 0.596 & & & \\
\hline Age (years) & -0.12 & 0.05 & -0.19 & -2.57 & $0.011^{*}$ & & & \\
\hline Origin & -0.27 & 0.47 & -0.03 & -0.57 & 0.570 & & & \\
\hline Place of residence & -0.24 & 1.13 & -0.01 & -0.22 & 0.829 & & & \\
\hline Marital status & -0.63 & 1.15 & -0.04 & -0.55 & 0.584 & & & \\
\hline Level of education & 0.50 & 0.68 & 0.04 & 0.73 & 0.465 & & & \\
\hline
\end{tabular}

Note: $\mathrm{n}=403 ;{ }^{*} p<0.05$ (significant); ${ }^{* * *} p<0.00$ I (significant). ${ }^{\dagger}$ Number of pastoral visits received in the last year; ${ }^{*}$ Training on healthy eating in the last year.

Abbreviations: B, beta coefficient; SE, standard error; $\beta$, coefficient of each independent variable by regression; ORA, organized religious activities; NORA, non-organized religious activities; IR, intrinsic religiosity.

explained by the fact that high dietary self-efficacy is inherent in SDA Church doctrine. In addition, it is possible that Adventists would have learned of the importance of eating a healthy diet through the Bible studies they generally receive before being baptized and becoming members of the church; this would have favored the fact that many already practice it regardless of their level of religiosity, as shown by the results, where $73 \%$ presented a high dietary self-efficacy. However, the dimensions of religiosity, as they relate to health, are a strong predictor of healthy eating behaviors; ${ }^{32}$ in addition, studies show that there are positive associations between private religiosity and healthy lifestyle behaviors, including discouraging the adoption of smoking. ${ }^{32}$ Furthermore, in our study, although there was no significance, the non-organized religious activities dimension was the strongest predictor of dietary self-efficacy.

On the other hand, dietary self-efficacy was significantly negatively associated with organized religious activities, non-organized religious activities, and intrinsic religiosity in members of the Seventh-day Adventist Church in Peru. In addition, all three dimensions of religiosity were associated with participation in healthy eating training activities in the past year, which is consistent with other research findings where religiosity played an important role in participation in activities that promote health and physical well-being. ${ }^{27}$ One of the ways to improve the eating habits of religious people is to promote their participation in related activities. ${ }^{27}$ In addition, people who participate in religious activities such as attending a church/mosque and practicing prayer/meditation may have healthy dietary patterns. ${ }^{15}$ These results corroborate the findings of previous studies demonstrating that people who participate in religious services are more likely to have healthy lifestyle habits. ${ }^{33,34}$

The SDA Church, within its philosophy and considering the health principles of the Bible and the Spirit of Prophecy, believes in the sanctification of the body as a temple of the Holy Spirit (1 Corinthians 6:19). Therefore, the SDA church, through its health and wellness programs, encourages members to adapt healthy lifestyle practices via the implementation of educational programs that include education on healthy eating and nutrition (consumption of healthy foods such as fruits, vegetables, nuts, among others), adequate rest and water consumption, outdoor exposure (air, sunlight), practice of regular physical activity, temperance (the moderate and intelligent use of all that is good and abstinence from all that is harmful), and the consequences of the consumption of stimulants such as narcotics, tea and coffee on health. ${ }^{35}$ These activities are aimed at improving health from its integral dimensions (bio-psycho-social of man) ${ }^{36}$ In this sense, like other dimensions of the religiosity variable, one of the proposed links between private religiosity and positive health 
outcomes is the practice of health-promoting behaviors and the avoidance of risky behaviors for physical, mental, and spiritual well-being. In the same vein, compared to other denominations or the general population, SDAs have a lower risk of diseases related to inadequate lifestyle; moreover, they are distinguished by their longevity. ${ }^{37}$ This could be due to the lifestyle recommendations and ordinances of the SDA Church and the fact that SDAs follow certain principles set forth in the Bible that prevent various diseases. ${ }^{27}$

The results showed that more than half of the SDAs surveyed presented high dietary self-efficacy. These findings are consistent with a similar study that reported improved dietary habit scores and a daily intake of more than five servings of fruit in $42 \%$ of participants; in addition, they reported that the average daily fruit intake was approximately five servings for all participants. ${ }^{20}$ Additionally, the results of another study showed that Seventh-Day Adventists have healthier eating habits than the general population. ${ }^{23}$ These results could be due to the fact that a large percentage of this population chooses healthy diets, particularly vegetarian diets. ${ }^{35}$ Vegetarian diets are based on the abundant consumption of minimally processed plant-based foods ${ }^{38}$ and play a fundamental role in the prevention of non-communicable diseases such as some types of cancer, cardiovascular diseases, high blood pressure, obesity, and type 2 diabetes mellitus; in addition, plant-based diets favor a better quality of life. ${ }^{6}$ Possible justification for the health benefits of vegetarian diets may be due to the fact that they are characterized by a high consumption of healthy foods such as vegetables, fruits, whole grains, legumes, nuts and seeds. These foods are rich in fiber and bioactive elements, which can provide benefits for the prevention, control, and treatment of various diseases. ${ }^{39}$ In addition, for many SDAs, being vegetarian is not limited to the consumption of plant-based foods, but rather, it is a lifestyle that includes regular physical activity, adequate sleep, water consumption, and participation in social and spiritual activities that promote social, emotional, and spiritual health. ${ }^{40}$ SDAs adhere to most of the lifestyle practices promoted by the SDA Church and are known to have a longer life expectancy and a lower likelihood of cardiovascular disease, cancer, and diabetes. ${ }^{41}$

The practical importance of this study lies in the fact that we found a high religiosity score among Seventh-Day Adventists in Peru. In fact, Peru, as a secular state, has a strong religious heritage and is one of the most religious countries in the Latin American region ( $82 \%$ of the population).$^{42}$ Religious beliefs are of great interest because they regulate eating behaviors, social relations, and consumption of harmful substances. ${ }^{20,43}$ In particular, religious attendance may be an activity that should be encouraged, as it can promote the abandonment of inappropriate habits and, therefore, generate potential health benefits. ${ }^{33}$ Therefore, religion should be given attention to its individual expression and its communitarian connotations, because the presence or absence of religious beliefs and practices can contribute to the modification of morbidity and mortality rates, favoring the preservation of health and quality of life, and can even increase life expectancy. ${ }^{17,44}$ On the other hand, health professionals, in their work, must consider the fact of the absence or presence of religious beliefs in the people over whom they exercise the functions of health promotion and prevention, ${ }^{45}$ because a greater knowledge of these aspects and other cognitions that accompany it, such as those related to health, will favor better collaboration and good results at any level of care at which we work. ${ }^{17}$

Finally, churches have an essential role to play in addressing the main social determinants of health in communities. In fact, church-based health education and promotion activities are gaining increasing attention as an effective strategy to promote healthy lifestyles and address health problems related to inappropriate behaviors, particularly unhealthy dietary habits. ${ }^{46}$ To ensure the success of these interventions, churches should work in partnership with universities and health communication centers to serve the population in their closest environment. ${ }^{46}$ In the United States, churches have been particularly active with African Americans; in Peru, although little has been explored about the role of the church in the community, the Seventh-Day Adventist Church, through joint work with the Peruvian Union University and agreements signed with Peruvian state entities (for example, the Peruvian Ministry of Health and Petroperu), has committed itself to many indigenous communities and rural population centers, carrying out health promotion and disease prevention activities. ${ }^{47,48}$

\section{Strengths and Limitations}

The results of this study should be interpreted considering certain limitations. The use of self-administered questionnaires in this cross-sectional study may generate social desirability bias. Similarly, our sample was relatively small, self-selected, and consisted mainly of fairly educated Adventists, this may not be representative of the entire Seventh-Day Adventist population in Peru, and this limits the generalizability of the results to other contexts. In addition, there are likely to be some differences 
in terms of characteristics and results between Adventists who responded to the survey and those who declined to participate in the study. Moreover, this is a cross-sectional study, so we cannot draw causal conclusions. Future research should consider a longitudinal design to establish causal associations between religiosity and dietary self-efficacy. On the other hand, we only included three measures of religiosity, which is a multidimensional construct; other important dimensions such as Sabbath observance, religious coping, and religious support, were not included in this study. Finally, we have not included elements of spirituality. However, despite these limitations, it is worth mentioning that this is the first study that has studied the relationship between religiosity and dietary efficacy in Seventh-Day Adventists in Peru.

\section{Conclusions}

In this study, we have shown that dietary self-efficacy was significantly negatively associated with organized religious activities, non-organized religious activities, and intrinsic religiosity in members of the Seventh-day Adventist Church in Peru. The non-organized religious activities dimension was the strongest predictor of dietary self-efficacy. Furthermore, all three dimensions of religiosity were associated with participation in training activities on healthy eating in the last year. Finally, the present study provides relevant information and an overview of religiosity and dietary aspect, since in recent years' worldwide studies are being carried out with greater care and thoroughness in this field due to the impact on healthy lifestyles. There is a need for research on the likely effect of religious behavior and health improvement regardless of religion and addressing it respectfully.

\section{Ethical Approval}

The study was approved by the Research Ethics Committee of the Faculty of Health Sciences of Universidad Peruana Unión: approval number: 032-2021/UPeU/FCS. Data collection was performed in accordance with the international regulations established in the Declaration of Helsinki.

\section{Disclosure}

Jacksaint Saintila, Yaquelin E. Calizaya-Milla, Digna E. Brañes-Ruiz, Pedro R. Nunura-Figueroa, Treisy C. ChávezHernández, Vasthy A. Bautista-Mayuri, Luz NR. Santisteban-Murga, and Sergio E. Calizaya-Milla are members of the Seventh-day Adventist Church. Jacksaint Saintila, Yaquelin E Calizaya-Milla, Digna E Brañes-Ruiz, Pedro R. NunuraFigueroa, and Sergio E Calizaya-Milla are employed by a university affiliated with the SDA Church. The authors report no other conflicts of itnerest in this work.

\section{References}

1. Kulik N, Thomas EM, Fahlman MM, et al. Dietary self-efficacy and dietary intake by race/ethnicity among elementary school children. Health Educ J. 2019;78(4):486-493. doi:10.1177/0017896918824138

2. Martínez-Alvarado JR, Palacios LHA, Rodríguez AGM, Asadi AA, Pérez KM. Analysis of the psychometric properties of the Mexican version of the dieting self-efficacy scale (DIET-SE). Nutr Hosp. 2019;36(3):723-728. doi:10.20960/nh.02470

3. Pan American Health Organization (PAHO). Noncommunicable diseases progress monitor 2020. Scorecard for the Americas. PAHO; 2020. Available from: https://iris.paho.org/handle/10665.2/51952. Accessed May 4, 2021.

4. EsSalud. Heart Disease Is the Leading Cause of Death in Adults.. Lima, Perú; 2019. Available from: http://www.essalud.gob.pe/. Accessed March 13,2021

5. Instituto Nacional de Estadística e Informática (INEI). 39.9\% of Peruvians aged 15 years and older have at least one comorbidity.; 2020. Available from: https://www.inei.gob.pe/prensa/noticias/el-399-de-peruanos-de-15-y-mas-anos-de-edad-tiene-al-menos-una-comorbilidad-12903/. Accessed February 3, 2022.

6. Saintila J, Lozano TE, Ruiz PG, White M, Huancahuire-Vega S. Health-related quality of life, blood pressure, and biochemical and anthropometric profile in vegetarians and nonvegetarians. J Nutr Metab. 2020;2020:1-8. doi:10.1155/2020/3629742

7. Sala-Vila A, Estruch R, Ros E. New insights into the role of nutrition in CVD prevention. Curr Cardiol Rep. 2015;17(5):1-11. doi:10.1007/s11886$015-0583-y$

8. Srour B, Fezeu LK, Kesse-Guyot E, et al. Ultra-processed food intake and risk of cardiovascular disease: prospective cohort study (NutriNet-Santé) BMJ. 2019;365:11451. doi:10.1136/bmj.11451

9. Lopez-Lopez DE, Saavedra-Roman IK, Calizaya-Milla YE, Saintila J. Food addiction, saturated fat intake, and body mass index in Peruvian adults: a cross-sectional survey. J Nutr Metab. 2021;2021:1-7. doi:10.1155/2021/9964143

10. Srour B, Fezeu LK, Kesse-Guyot E, et al. Ultraprocessed food consumption and risk of type 2 diabetes among participants of the Nutrinet-Santé prospective cohort. JAMA Intern Med. 2020;180(2):283-291. doi:10.1001/jamainternmed.2019.5942

11. Fiolet T, Srour B, Sellem L, et al. Consumption of ultra-processed foods and cancer risk: results from NutriNet-Santé prospective cohort. BMJ. 2018;360:k322. doi:10.1136/bmj.k322 
12. Blanco-Rojo R, Sandoval-Insausti H, López-Garcia E, et al. Consumption of ultra-processed foods and mortality: a national prospective cohort in Spain. Mayo Clin Proc. 2019;94(11):2178-2188. doi:10.1016/j.mayocp.2019.03.035

13. Koenig HG, King D, Carson VB. Handbook of Religion and Health. USA: OUP; 2012.

14. Parker M, Roff LL, Klemmack DL, Koenig HG, Baker P, Allman RM. Religiosity and mental health in southern, community-dwelling older adults. Aging Ment Health. 2003;7(5):390-397. doi:10.1080/1360786031000150667

15. Svensson NH, Hvidt NC, Nissen SP, et al. Religiosity and health-related risk behaviours in a secular culture--Is there a correlation? $J$ Relig Health. 2020;59(5):2381. doi:10.1007/S10943-019-00919-2

16. Tan M-M, Chan CKY, Reidpath DD. Religiosity and spirituality and the intake of fruit, vegetable, and fat: a systematic review. Evid-Based Complement Altern Med. 2013;2013:1-18. doi:10.1155/2013/146214

17. Abu H, Ulbricht C, Ding E, et al. Association of religiosity and spirituality with quality of life in patients with cardiovascular disease: a systematic review. Qual Life Res. 2018;27(11):2777-2797. doi:10.1007/s11136-018-1906-4

18. Gillum F, Williams C. Associations between breast cancer risk factors and religiousness in American women in a national health survey. $J$ Relig Health. 2009;48(2):178-188. doi:10.1007/s10943-008-9187-9

19. Charlemagne-Badal SJ, Lee JW. Intrinsic religiosity and hypertension among older North American Seventh-Day Adventists. $J$ Relig Health. 2016;55(2):695-708. doi:10.1007/s10943-015-0102-x

20. Tan MM, Chan CKY, Reidpath DD. Religiosity, dietary habit, intake of fruit and vegetable, and vegetarian status among Seventh-Day Adventists in West Malaysia. J Behav Med. 2016;39(4):675-686. doi:10.1007/s10865-016-9736-8

21. Ansari S, Soltero EG, Lorenzo E, Lee RE. The impact of religiosity on dietary habits and physical activity in minority women participating in the Health is Power (HIP) study. Prev Med Rep. 2017;5:210-213. doi:10.1016/j.pmedr.2016.12.012

22. Sabaté J. Religion, diet and research. Br J Nutr. 2004;92(2):199-201. doi:10.1079/bjn20041229

23. Mills PK, Beeson WL, Phillips RL, Fraser GE. Cancer incidence among California Seventh-day Adventists, 1976-1982. Am J Clin Nutr. 1994;59 (5):1136S-1142S. doi:10.1093/ajen/59.5.1136S

24. Baruth M, Wilcox S, Condrasky MD. Perceived environmental church support is associated with dietary practices among African-American adults. $J$ Am Diet Assoc. 2011;111(6):889-893. doi:10.1016/j.jada.2011.03.014

25. Matsumoto S, Beeson WL, Shavlik DJ, et al. Association between vegetarian diets and cardiovascular risk factors in non-Hispanic white participants of the Adventist Health Study-2. J Nutr Sci. 2019;8:e6. doi:10.1017/jns.2019.1

26. Segovia-Siapco G, Sabaté J. Health and sustainability outcomes of vegetarian dietary patterns: a revisit of the EPIC-Oxford and the Adventist Health Study-2 cohorts. Eur J Clin Nutr. 2018;72(Suppl1). doi:10.1038/s41430-018-0310-z

27. McKenzie MM, Modeste NN, Marshak HH, Wilson C. Religious involvement and health-related behaviors among black Seventh-Day Adventists in Canada. Health Promot Pract. 2015;16(2):264-270. doi:10.1177/1524839914532812

28. Koenig HG, Büssing A. The Duke University Religion Index (DUREL): a five-item measure for use in epidemiological studies. Religions. 2010;1 (1):78-85. doi:10.3390/rel1010078

29. Wansley Taylor P. Psychometric properties of the Duke University religion index, English and Spanish versions, for Hispanic-American women; 2013.

30. Stich C, Knauper B, Tint A. A scenario-based dieting self-efficacy scale: the DIET-SE. Assessment. 2009;16(1):16-30. doi:10.1177/ 1073191108322000

31. Iglesia Adventista del Séptimo Día. Church Manual.; 2015. Available from: http://www.pcsda.org/wp-content/uploads/2014/10/Manual-de-laIglesia-Adventista-19-Revision-Revision-2015.pdf. Accessed November 19, 2021.

32. Nonnemaker J, McNeely CA, Blum RW. Public and private domains of religiosity and adolescent smoking transitions. Soc Sci Med. 2006;62 (12):3084-3095. doi:10.1016/j.socscimed.2005.11.052

33. Brown QL, Linton SL, Harrell PT, et al. The influence of religious attendance on smoking. Subst Use Misuse. 2014;49(11):1392-1399. doi:10.3109/10826084.2014.912224

34. Kobayashi D, Shimbo T, Takahashi O, Davis RB, Wee CC. The relationship between religiosity and cardiovascular risk factors in Japan: a large-scale cohort study. J Am Soc Hypertens. 2015;9(7):553-562. doi:10.1016/j.jash.2015.04.003

35. Banta JE, Lee JW, Hodgkin G, Yi Z, Fanica A, Sabate J. The global influence of the Seventh-day Adventist Church on diet. Religions. 2018;9 (9):251. doi:10.3390/rel9090251

36. Seventh-Day Adventist Church. Fundamental beliefs; 2013. Available from: http://www.adventist.org/beliefs/fundamental/index.html. Accessed November 18, 2021

37. Jacobsen BK, Knutsen SF, Oda K, Fraser GE. Parity and total, ischemic heart disease and stroke mortality. the Adventist Health Study, $1976-1988$. Eur J Epidemiol. 2011;26(9):711-718. doi:10.1007/s10654-011-9598-x

38. Saintila J, Calizaya-Milla YE, Javier-Aliaga DJ. Knowledge of vegetarian and nonvegetarian Peruvian dietitians about vegetarianism at different stages of life. Nutr Metab Insights. 2021;14:117863882199712. doi:10.1177/1178638821997123

39. Saintila J, López TEL, Calizaya-Milla YE, Huancahuire-Vega S, White M. Nutritional knowledge, anthropometric profile, total cholesterol, and motivations among Peruvian vegetarians and non-vegetarians. Nutr Clin Diet Hosp. 2020;41(1):91-98. doi:10.12873/411SAINTILA

40. Le LT, Sabaté J, Singh PN, Jaceldo-Siegl K. The design, development and evaluation of the vegetarian lifestyle index on dietary patterns among vegetarians and non-vegetarians. Nutrients. 2018;10(5):542. doi:10.3390/nu10050542

41. Montgomery S, Herring P, Yancey A, et al. Comparing self-reported disease outcomes, diet, and lifestyles in a national cohort of black and white Seventh-day Adventists. Prev Chronic Dis. 2007;4(3):A62.

42. Macías R. Religious expressions in Latin America and Italy. Presentación del dossier. Cuicuilco Rev Cienc Antropol. 2020;27:S2448.

43. Pitel L, Geckova AM, Kolarcik P, Halama P, Reijneveld SA, van Dijk JP. Gender differences in the relationship between religiosity and health-related behaviour among adolescents. J Epidemiol Community Health. 2012;66(12):1122-1128. doi:10.1136/jech-2011-200914

44. Jedrychowski W, Tobiasz-Adamczyk B, Olma A, Gradzikiewicz P. Survival rates among Seventh Day Adventists compared with the general population in Poland. Scand J Public Health. 1985;13(2):49-52. doi:10.1177/140349488501300201

45. Fuchs JR, Fuchs JW, Hauser JM, Coors ME. Patient perspectives on religiously affiliated care in rural and urban Colorado. J Prim Care Commun Health. 2021;12. doi:10.1177/21501327211012158. 
46. Ayton D, Manderson L, Smith BJ, Carey G. Health promotion in local churches in Victoria: an exploratory study. Health Soc Care Community. 2016;24(6):728-738. doi:10.1111/HSC.12258

47. Ministerio de salud (MINSA). Agreement 095-2021-MINSA - Gobierno del Perú; 2021. Available from: https://www.gob.pe/institucion/minsa/ normas-legales/2192286-095-2021-minsa. Accessed November 18, 2021.

48. Petroperú SA. Annual Report 2020; 2020. Available from: https://petroperu.com.pe/Storage/tbl_documentos_varios/fld_1160_Documento_file/630p9Bw8Zz6Ic3Tf8D.pdf. Accessed November 18, 2021.

\section{Publish your work in this journal}

The Journal of Multidisciplinary Healthcare is an international, peer-reviewed open-access journal that aims to represent and publish research in healthcare areas delivered by practitioners of different disciplines. This includes studies and reviews conducted by multidisciplinary teams as well as research which evaluates the results or conduct of such teams or healthcare processes in general. The journal covers a very wide range of areas and welcomes submissions from practitioners at all levels, from all over the world. The manuscript management system is completely online and includes a very quick and fair peer-review system. Visit http://www.dovepress.com/testimonials.php to read real quotes from published authors.

Submit your manuscript here: https://www.dovepress.com/journal-of-inflammation-research-journal 